\title{
Community acquired pneumonia in adults: a study comparing clinical features and outcome in Africa (Republic of Guinea) and Europe (France)
}

O Sow, M Frechet, A A Diallo, S Soumah, M K Conde, P Diot, E Boissinot, E Lemarié

\begin{abstract}
Background - Community acquired pneumonia is the most common cause of death from infectious disease both in western and developing countries. A study was carried out in Conakry, Republic of Guinea and Tours, France in order to compare signs, symptoms, severity of illness, risk factors, and clinical outcome of community acquired pneumonia in adult patients admitted to hospital.

Methods - The study was performed in the cities of Conakry and Tours over the same one year period. Patients with nosocomial pneumonia, tuberculosis, and those who were HIV positive were excluded. Data were recorded on the same forms in both centres. A severity score was calculated according to American Thoracic Society criteria. Follow up was evaluated at days 2, 7 and 15.
\end{abstract}

Results - A total of 333 patients (218 from Conakry, 115 from Tours) were included in the study with a diagnosis of community acquired pneumonia, with or without lung abscess or pleural effusion. Mean age was higher and pre-existing illness rate, dehydration, agitation, and stupor were more frequent in patients in Tours. Respiration rates of $>30$ breaths $/ \mathrm{min}$ and the incidence of crackles were identical in the two centres. Fever above $39^{\circ} \mathrm{C}$, initial shock, chest pain, and herpes were significantly more frequent in Conakry. Initial chest radiographic abnormalities were similar in the two groups, ranging from unilateral pleuropulmonary involvement (89\% and $83 \%$ in Conakry and Tours, respectively) to diffuse patchy parenchymal disease. Parapneumonic effusion was present in $17 \%$ and $16 \%$ of the patients of Conakry and Tours, respectively. Pneumonia was considered to be severe in $33 \%$ and $42 \%$ of the patients, respectively. In Conakry first line antibiotic therapy was penicillin alone ( 2 million units a day) for 197 patients $(90 \%)$ and second line antibiotic therapy was prescribed for 25 patients $(12 \%)$. In Tours first line therapy consisted of a single antibiotic (amoxicillin, third generation cephalosporins) for 65 patients $(57 \%)$ and second line antibiotic therapy was prescribed for 55 patients $(48 \%)$. The clinical outcome was similar in Conakry and Tours: $88 \%$ and $85 \%$ of patients, respectively, were afebrile or clinically cured at day 15 . The mortality rate was similar ( $6 \%$ and $8 \%$, respectively). Conclusions - The problems encountered in the management of community acquired pneumonia are quite different in western and developing countries. This study shows that low doses of penicillin can cure $90 \%$ of African patients with pneumonia as effectively as more aggressive treatments in European patients who are both older and have greater comorbidity. Although pneumococci with reduced penicillin sensitivity occur in western countries, this does not seem to be the case in black Africa. For these reasons, low doses of penicillin or amoxicillin remain good first line treatment.

(Thorax 1996;51:385-388)

Keywords: respiratory infection, Africa, adult.

Acute respiratory infections, especially bacterial pneumonia, constitute the major cause of mortality and morbidity among children below 5 years of age in developing countries. ${ }^{1-3}$ The mortality from pneumonia deaths in Peru is 37 times higher in infants and 43 times higher in children aged 1-4 years than in North America. ${ }^{4}$ In adult patients, especially in Africa, few data are available concerning the overall incidence, severity of illness, prognostic factors, and efficacy of antibiotic treatment in community acquired pneumonia.

In Africa patients are usually treated with low doses of penicillin only, without identification of the causative organism. In western countries a number of new pathogens have been identified and newer antimicrobial agents are available. In addition, there have been changes in the pattern of antibiotic resistance, especially for Streptococcus pneumoniae. ${ }^{56}$

This study was carried out in Conakry, Republic of Guinea and Tours, France in order to compare signs, symptoms, severity of illness, risk factors and clinical outcome of community acquired pneumonia in adult patients admitted to hospital.

Methods

The study was performed over a one year period from March 1992 to March 1993. Adult 
patients were diagnosed as having community acquired pneumonia if they had respiratory symptoms (cough, dyspnoea, or chest pain), fever, and new densities on pulmonary radiographs. Patients with nosocomial pneumonia, tuberculosis, and those who were HIV positive were excluded from the study.

The Republic of Guinea is a West African republic with a population of approximately 7.2 million of whom 1.5 million live in the capital, Conakry. The country has a subtropical climate and socioeconomic status is low with poor sanitation and crowded living conditions. The data were collected from the Department of Chest Diseases of the Centre Hospitalier Universitaire of Conakry. Adults were examined by one of the three chest physicians for symptoms of community acquired pneumonia and all required admission to hospital. Physicians participating in the study were trained to conduct the clinical study and to collect relevant data. A chest radiograph was performed in all patients with signs of pneumonia. Other laboratory investigations were carried out by the attending physicians. Patients were all treated according to an acute respiratory infection protocol established by the Department of Chest Diseases. First line antibiotic therapy consisted of penicillin ( 2 million units per day). In patients with parapneumonic pleural effusion, lung abscess, or severe infection a combination of penicillin ( 2 million units per day) with an aminoglycoside or metronidazole was recommended.

Tours is a town of 200000 inhabitants in the centre of France. The data were collected from the Department of Chest Diseases of the Centre Hospitalier Universitaire during the same one year period. All patients with community acquired pneumonia requiring ad-

Table 1 Data of history and physical examination of patients with community acquired pneumonia in Conakry and Tours

\begin{tabular}{|c|c|c|c|}
\hline \multirow[t]{2}{*}{ Centre } & \multicolumn{2}{|c|}{ Number (\%) of cases } & \multirow[t]{2}{*}{ p value } \\
\hline & $\begin{array}{l}\text { Conakry } \\
(n=218)\end{array}$ & $\begin{array}{l}\text { Tours } \\
(n=115)\end{array}$ & \\
\hline $\begin{array}{l}\text { Mean }(S D) \text { age } \\
\text { No. }>55 \text { years }\end{array}$ & $\begin{array}{l}38(16) \\
33(15)\end{array}$ & $\begin{array}{l}62(23) \\
75(65)\end{array}$ & $\begin{array}{l}<0.001 \\
<0.001\end{array}$ \\
\hline $\begin{array}{l}\text { Sex } \\
\text { Men } \\
\text { Women }\end{array}$ & $\begin{array}{r}173(79) \\
45(20)\end{array}$ & $\begin{array}{l}69(60) \\
46(40)\end{array}$ & $<0.001$ \\
\hline $\begin{array}{l}\text { Pre-existing illnesses } \\
\text { COPD } \\
\text { Malignancy } \\
\text { Cardiac insufficiency } \\
\text { Chronic liver disease } \\
\text { Neuropsychiatric disease }\end{array}$ & $\begin{array}{l}2(1) \\
0 \\
3(2) \\
4(2) \\
1\end{array}$ & $\begin{aligned} & 15(13) \\
& 16(14) \\
& 9(8) \\
& 2(2) \\
& 22(19)\end{aligned}$ & $\begin{array}{l}<0.001 \\
<0.001 \\
<0.01 \\
\text { NS } \\
<0.0001\end{array}$ \\
\hline $\begin{array}{l}\text { Symptoms and signs } \\
\text { Dehydration } \\
\text { Diarrhoea } \\
\text { Fever } \geq 39^{\circ} \mathrm{C} \\
\text { Chest pain } \\
\text { Dyspnoea* } \\
\text { Agitation, stupor } \\
\text { Initial shock** } \\
\text { Purulent expectoration } \\
\text { Haemoptysis } \\
\text { Bronchial breathing } \\
\text { Crackles } \\
\text { Cervical adenopathy } \\
\text { Herpes } \\
\text { Hepatomegaly } \\
\text { Jaundice }\end{array}$ & $\begin{aligned} 12(5) \\
15(7) \\
148(68) \\
211(96) \\
58(27) \\
7(4) \\
54(25) \\
80(36) \\
11(5) \\
7(3) \\
155(70) \\
1( \\
20(9) \\
4(2) \\
7(3)\end{aligned}$ & $\begin{array}{c}17(15) \\
8(7) \\
57(50) \\
55(48) \\
40(35) \\
15(13) \\
12(10) \\
53(46) \\
13(11) \\
31(27) \\
72(63) \\
0 \\
1(1) \\
4(3) \\
3(3)\end{array}$ & $\begin{array}{l}<0 \cdot 01 \\
\text { NS } \\
<0 \cdot 01 \\
<0 \cdot 001 \\
\text { NS } \\
<0 \cdot 01 \\
<0 \cdot 01 \\
\text { NS } \\
\text { NS } \\
<0 \cdot 001 \\
\text { NS } \\
\text { NS } \\
<0 \cdot 01 \\
\text { NS } \\
\text { NS }\end{array}$ \\
\hline
\end{tabular}

$\mathrm{COPD}=$ chronic obstructive pulmonary disease.

* Respiration rate $>30$ breaths $/ \mathrm{min}$.

** Shock = systolic blood pressure below $90 \mathrm{~mm} \mathrm{Hg}$ or diastolic blood pressure below $60 \mathrm{~mm} \mathrm{Hg}$. mission to hospital were included in the study. Critically ill patients admitted directly to the intensive care unit were excluded from the study.

Case histories and physical and diagnostic tests were recorded on the same study forms in Conakry and Tours. Blood culture, protected brush catheter sampling at bronchoscopy, and pleural fluid aspiration for microbiology were only performed in Tours.

As in other studies, the presence of comorbid conditions that may affect the prognosis was recorded. ${ }^{78}$ Investigators were trained according to American Thoracic Society criteria ${ }^{5}$ to evaluate severity scores in adults. Although there is no universally accepted definition of severe community acquired pneumonia, the presence of at least one of the following justified defining the pneumonia as severe: (1) respiration rate above 30 breaths $/ \mathrm{min}$ at admission, (2) severe respiratory failure defined by a $\mathrm{PaO}_{2} / \mathrm{FiO}_{2}$ ratio less than $33 \mathrm{kPa}$, (3) need for mechanical ventilation, (4) chest radiograph showing bilateral involvement or involvement of multiple lobes, (5) shock (systolic blood pressure below $90 \mathrm{~mm} \mathrm{Hg}$ or diastolic blood pressure below $60 \mathrm{~mm} \mathrm{Hg}$ ), (6) need for vasopressors for more than four hours, and (7) urine output of $<20 \mathrm{ml} /$ hour or total urine output of $<80 \mathrm{ml}$ in four hours. Evaluation of the $\mathrm{PaO}_{2} / \mathrm{FiO}_{2}$ ratio, mechanical ventilation, and vasopressors was impossible in Conakry, and therefore to allow comparison to be made between Tours and Conakry patients were categorised as having severe infection when at least one of the criteria 1, 4, or 5 was present. Patients were evaluated at days 2,7 , and 15 and the presence or absence of fever was recorded.

\section{DATA ANALYSIS}

Statistical analysis was performed using the $\chi^{2}$ test to calculate the differences in distribution of clinical signs and symptoms between the groups. To investigate the association of clinical signs and symptoms with age, patients were stratified into two groups taking a cutoff figure of 55 years (Mantel-Haetzel test). A p value of $<0.05$ was considered significant.

\section{Results}

A total of 333 patients aged $>15$ years (218 in Conakry, 115 in Tours) with a diagnosis of community acquired pneumonia, with or without complications such as lung abscess or pleural effusion, were included in the study.

Table 1 summarises the history and physical examination of the two populations. Mean age and pre-existing illness rate were significantly lower in Conakry than in Tours. Initial fever above $39^{\circ} \mathrm{C}$, shock at presentation, chest pain, and herpes were significantly more frequent in patients in Conakry than those in Tours, while bronchial breathing, dehydration, agitation, and stupor were significantly more frequent in Tours. The numbers of patients with a respiratory rate of $>30$ breaths $/ \mathrm{min}$, crackles, and abnormalities of liver function were identical in the two centres. Thirty three patients in 
Table 2 Radiological and biological data of patients with community acquired pneumonia in Conakry and Tours

\begin{tabular}{|c|c|c|}
\hline \multirow[t]{2}{*}{ Centre } & \multicolumn{2}{|c|}{ Number (\%) of cases } \\
\hline & $\begin{array}{l}\text { Conakry } \\
(n=218)\end{array}$ & $\begin{array}{l}\text { Tours } \\
(n=115)\end{array}$ \\
\hline $\begin{array}{l}\text { Chest radiography: } \\
\text { One lung involved } \\
\text { Both lungs involved } \\
\text { Cavitation } \\
\text { Pleural fluid } \\
\text { Hilar adenopathies }\end{array}$ & $\begin{array}{r}194(89) \\
24(11) \\
10(5) \\
38(17) \\
0\end{array}$ & $\begin{array}{c}95(83) \\
20(17) \\
9(8) \\
18(16) \\
0\end{array}$ \\
\hline $\begin{array}{l}\text { Microbiological methods: } \\
\text { Blood culture } \\
\text { No. positive } \\
\text { Pleural fluid } \\
\text { No. positive } \\
\text { Protected brush } \\
\text { No. positive }\end{array}$ & $\begin{array}{l}0 \\
0 \\
0\end{array}$ & $\begin{array}{l}101(88) \\
14(12) \\
18 \\
13 \\
36(31) \\
12\end{array}$ \\
\hline $\begin{array}{l}\text { Microbiological aetiology: } \\
\text { S pneumoniae } \\
\text { H influenzae } \\
\text { S aureus } \\
\text { Other streptococci } \\
\text { Pseudomonas species } \\
\text { Aerobic Gram negative bacilli } \\
\text { Anaerobes }\end{array}$ & 0 & $\begin{array}{r}29(25) \\
12 \\
6 \\
5 \\
5 \\
4 \\
4 \\
2\end{array}$ \\
\hline $\begin{array}{l}\text { Biological tests } \\
\mathrm{PaO}_{2} / \mathrm{FiO}_{2} \\
\mathrm{No} .<33 \mathrm{kPa}\end{array}$ & 0 & $\begin{array}{l}97(84) \\
49(43)\end{array}$ \\
\hline
\end{tabular}

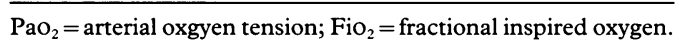

Conakry and 75 in Tours were older than 55 years. There was no significant association of any clinical signs or symptoms with age, taking a cutoff figure of 55 years.

Table 2 shows radiological and biological data. The initial chest radiographic abnormalities were similar in the two groups and ranged from unilateral lung involvement $(89 \%$ and $83 \%$ in Conakry and Tours, respectively) to bilateral or diffuse patchy parenchymal disease. Bilateral pneumonia was seen in $11 \%$ of patients in Conakry and $17 \%$ of patients in Tours. Parapneumonic effusions were present in $17 \%$ and $16 \%$ of the patients, respectively. In Tours, blood and pleural fluid specimens were obtained under routine clinical conditions and were examined in the local microbiology laboratory where Gram staining and cultures were performed. Bronchoscopic examination with protected brush catheter was performed in 36 patients (31\%) with severe illness. The microbiological aetiology was determined in $25 \%$ of the patients. Measurement of the $\mathrm{PaO}_{2} /$ $\mathrm{FiO}_{2}$ ratio was performed in Tours and 49 patients $(43 \%)$ had a ratio of $<33 \mathrm{kPa}$.

Table 3 Severity score, antibiotic therapy, and clinical outcome of patients with community acquired pneumonia in Conakry and Tours

\begin{tabular}{|c|c|c|c|}
\hline \multirow[t]{2}{*}{ Centre } & \multicolumn{2}{|c|}{ Number (\%) of cases } & \multirow[t]{2}{*}{$p$ value } \\
\hline & $\begin{array}{l}\text { Conakry } \\
(n=218)\end{array}$ & $\begin{array}{l}\text { Tours } \\
(n=115)\end{array}$ & \\
\hline $\begin{array}{l}\text { Severity score } \\
\text { Severe }\end{array}$ & $72(33)$ & $48(42)$ & NS \\
\hline $\begin{array}{l}\text { Antibiotic therapy } \\
\text { First line antibiotic }\end{array}$ & & & \\
\hline $\begin{array}{l}1 \text { antibiotic } \\
2 \text { antibiotics } \\
3 \text { antibiotics }\end{array}$ & $\begin{array}{c}202(93) \\
16(7)\end{array}$ & $\begin{array}{c}65(57) \\
45(39) \\
5(4)\end{array}$ & $<0 \cdot 001$ \\
\hline Second line antibiotic & $25(12)$ & $55(48)$ & $<0.001$ \\
\hline $\begin{array}{l}\text { Clinical outcome } \\
\text { Afebrile at day } 2-3^{*} \\
\text { Afebrile at day } 7^{*} \\
\text { Afebrile and/or cured at day } 15 \\
\text { Died }\end{array}$ & $\begin{array}{l}138(63) \\
142(65) \\
193(88) \\
13(6)\end{array}$ & $\begin{array}{l}80(69) \\
90(78) \\
98(85) \\
9(8)\end{array}$ & $\begin{array}{l}\text { NS } \\
<0 \cdot 02 \\
\text { NS } \\
\text { NS }\end{array}$ \\
\hline
\end{tabular}

* Temperature less than $37 \cdot 5^{\circ} \mathrm{C}$
Table 3 shows the severity score, antibiotic therapy, and clinical outcome of all patients. Pneumonia was considered to be severe in 72 patients $(33 \%)$ in Conakry and in 48 patients $(42 \%)$ in Tours (NS). In Tours nine patients with severe pneumonia were admitted initially to the Department of Chest Diseases and subsequently required intensive care treatment, two with mechanical ventilation. Addition of other severity criteria such as $\mathrm{PaO}_{2} / \mathrm{FiO}_{2}$ ratio, need for mechanical ventilation, and vasopressors only slightly increased the number of patients (51) classified as severe in Tours.

In Conakry first line antibiotic therapy was penicillin alone ( 2 million units per day) in 197 patients $(90 \%)$, a combintion of penicillin and an aminoglycoside or metronidazole in 14 patients $(6 \%)$, and another treatment regimen in seven patients. Second line antibiotic therapy (usually macrolides) was prescribed for 25 patients $(12 \%)$. In Tours first line therapy consisted of a single antibiotic (usually high dose amoxicillin or amoxicillin/clavulanate $(47 \%)$ or a third generation cephalosporin) in 65 patients $(57 \%)$. Another antibiotic in combination was prescribed in 45 patients (39\%), usually a fluorinated quinolone $(32 \%)$. Second line antibiotic therapy was prescribed for 55 patients $(48 \%)$; this was either the addition of another antibiotic, usually a fluorinated quinolone in 36 patients $(31 \%)$, or a change in antibiotic therapy $(17 \%)$, usually to a macrolide, following identification of the organism or drug intolerance or allergy.

Clinical outcome (table 3) was not significantly different between Conakry and Tours; $88 \%$ and $85 \%$ of patients, respectively, were afebrile or considered to be clinically cured at day 15. In Tours 13 patients died (mean age 73 ) of whom six had a previous diagnosis of congestive cardiac failure or chronic obstructive airway disease and seven had malignancy. In Conakry nine patients died (mean age 51), five with congestive cardiac failure or chronic obstructive pulmonary disease and four from respiratory failure with septic shock. The mortality rate was similar in both centres $-6 \%$ and $8 \%$ in Conakry and Tours, respectively.

\section{Discussion}

Compared with a European centre, patients with community acquired pneumonia managed in an African centre were younger and had a lower comorbidity rate. Differences in preexisting illness probably reflect the considerable difference in age. We have no explanation for the greater percentage of men in Conakry. We do not know how many patients were excluded from the study because of infection with HIV.

Severity score, clinical outcome and mortality rate are identical in the two cities. However, in Conakry admission was more often a consequence of pneumonia alone whereas in Tours the patients were older with significant comorbidity and admission may have been determined by other factors in some patients. In Conakry patients were younger, with some dying solely as a consequence of pneumonia, 
whereas in Tours they were older and died from a combination of pneumonia and their pre-existing illness. Comparison of disease severity between the two groups was made on the basis of easily measurable clinical parameters because of lack of access to sophisticated diagnostic and treatment facilities in Africa. However, the addition of these measures did not significantly increase the number of European patients classified as "severe", confirming that simple clinical assessment is a good measure of severity.

The microbial aetiology of pneumonia in Tours corresponds to results of prospective studies involving adults from both western Europe and North Americas: $S$ pneumoniae, $H$ influenzae, $S$ aureus and aerobic Gram negative bacilli are common among patients with community acquired pneumonia requiring admission to hospital but who are not critically ill. Few clinical and laboratory data are available for community acquired pneumonias in developing countries, especially Africa, ${ }^{6910}$ and unfortunately the microbial aetiology was not determined in Conakry. Many studies have suggested that it is difficult to predict the microbial aetiology on the basis of the presenting clinical features. ${ }^{112}$ We evaluated parameters such as herpes and chest pain, which are usually associated with pneumococcal pneumonia, and cervical adenopathy which is present in $25 \%$ of Mycoplasma pneumoniae infections. ${ }^{13}$ Chest pain and herpes were significantly more common in Conakry and implies that $S$ pneumoniae was the most common offending pathogen. ${ }^{14}$

This study shows that low doses of penicillin ( 2 million units per day) cures $90 \%$ of African patients with pneumonia as effectively as more aggressive treatment in European patients who were older and had comorbidity. Although pneumococci with reduced penicillin sensitivity occur in western countries, this does not yet seem to be the case in black Africa where low dose penicillin or amoxicilin remain good choices as first line treatment.

Financial support for this research was provided by the Mission de Cooperation Culturelle et Technique, Ambassade de France à Conakry and by a programme of Université François Rabelais, Tours.

The authors are grateful to B Barry for computing data and Doreen Raine for reviewing the English.

1 Leowski J. Mortality from acute respiratory infections in children under 5 years of age: global estimates. World Health Stat $Q$ 1986;39:138-44.

2 World Health Organisation. Case management of acute respiratory infections in children in developing countries. Geneva: WHO, 1985.

3 Working Group On ARI, Respiratory Disease Committee, International Union Against Tuberculosis and Lung Diseases. Acute respiratory infections: conclusions of an IUALTD workshop. Tubercle Lung Dis 1993;74:2-5.

4 Pan American Health Organization. Acute respiratory infections in the Americas. Epidemiol Bull 1980;1:1-4.

5 American Thoracic Society. Guidelines for the initial management of adults with community-acquired pneumonia:
diagnosis, assessment of severity, and initial antimicrobial therapy. Am Rev Respir Dis 1993;148:1418-26.

6 Graham N M H. The epidemiology of acute respiratory infections in children and adults: a global perspective. Epidemiol Rev 1990;12:149-78.

7 Fine $M$, Smith D, Singer D. Hospitalization decision in patients with community acquired pneumonia: a propatients with community acquired pneumonia:
spective cohort study. Am $\mathcal{F}$ Med 1990;89:713-21.

8 Farr BM, Sloman AJ, Fisch MJ. Predicting death in patients hospitalized for community-acquired pneumonia. Ann hospitalized for community-acc
Intern Med 1991;115:428-35.

9 Ikeogu MO. Acute pneumonia in Zimbabwe: bacterial isolates by lung aspirations. Arch Dis Child 1988;63:1266-7.

10 Aderaye G. Community acquired pneumonia in adults in Addis Ababa: etiologic agents and the impact of HIV infection. Tubercle Lung Dis 1994;75:308-12.

11 Farr BM, Kaiser DL, Harrison BDW, Connolly CK. Prediction of microbial aetiology at admission to hospital for pneumonia from the presenting clinical features. Thorax 1989;44:1031-5.

12 Levy M, Dromer F, Brion N, Leturdu F, Carbon C. Community-acquired pneumonia. Importance of initial noninvasive bacteriologic and radiologic investigations. Chest 1988;92:43-8.

13 Mansel JK, Rosenow EC, Smith TF, Martin JW. Mycoplasma pneumoniae pneumonia. Chest 1989;95:639-45.

14 Singal M, Hedges JR, Radack KL. Decision rules and clinical prediction of pneumonia: evaluation of low-yield criteria. Ann Emerg Med 1989;18:13-20. 